\title{
Investigation of the Effect of Organoclay Additives on Mechanical Properties of PF resin and MPB-OSL using Creep Behavior Analysis and IB Test*1
}

\author{
Yong Sik Kim*2 and John F. Kadla*3†
}

\begin{abstract}
The effect of organoclays on the mechanical properties of cured phenol formaldehyde resin and oriented strand lumber made from Mountain Pine Beetle killed pine strands was analyzed. Three organoclays were used: a natural montmorillonite, hydrophobic organically modified $10 \mathrm{~A}$, and hydrophilic organically modified $30 \mathrm{~B}$. The oriented strand lumber samples were less creep deformation as well as improved internal bonding strength by adding organoclays in the order of 10 A $2 \%>$ MMT $2 \%>30$ B $2 \%>$ control. Furthermore, time-temperature superposition (TTS) analysis was proved to be able to predict the long-term creep behavior of MPB-OSL samples.
\end{abstract}

Keywords : creep behavior, organoclay, internal bonding, MPB-killed pine, oriented strand lumber (OSL), time-temperature superposition (TTS)

\section{INTRODUCTION}

Lodgepole pine (Pinus contorta) is a major wood species used to produce wood composites in Western Canada. However, approximately 4.2 million hectares of the total 8 million hectares of mature lodgepole pine in the central interior of British Columbia has been infested by the Mountain Pine Beetle (MPB, Dendroctonus ponderosae Hopkins) (Morford et al., 2004; Natural Resource Canada, 2004). To maximize the value from the pine forests, most forest product companies in the province have been harvesting green timber. This will inevitably re- sult in an enormous amount of MPB infested wood, potentially not suitable for traditional wood products. However, the large amount of MPB infested wood could be utilized for wood composite products, one possible end-use being oriented strand lumber (MPB-OSL) (Feng et al., 2007; Oudjehane et al., 2008 2009).

Recently, nano-fillers have been receiving significant attention due to their ability to improve mechanical properties and thermal stability of composite materials (Pinnavaia et al., 2000; Lei et al., 2006; Lin et al., 2005; Lei et al., 2007) Organoclay/polymer composites have exhibited dramatic increases in strength, barrier

*1 Received on March 9, 2011; accepted on April 4, 2011

*2 Division of Forest Bioenery, Bioenergy Research Center, Korea Forest Research Institute, Seoul 130-712, Korea

*3 Department of Wood Science, Faculty of Forestry, The University of British Columbia, Vancouver, BC, Canada

† Corresponding author : John F. Kadla (e-mail: john.kadla@ubc.ca) 


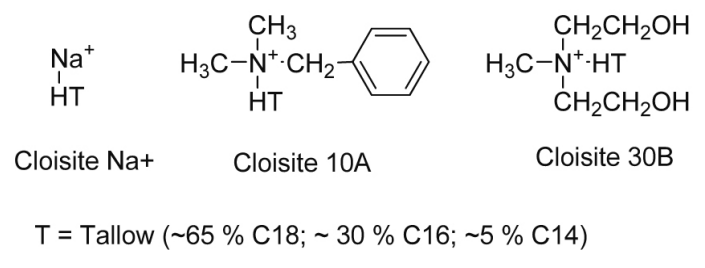

Fig. 1. Chemical structures of organoclays.

properties, flammability resistance, and heat resistance compared with conventional composites (Lei et al., 2006). Work by Lin et al. (2005) and Lei et al. $(2006,2007)$ on wood-plastic composites and particleboard has shown that a $1 \%$ addition of nanoclay can yield a strength increase as high as $20 \%$. Used as an additive to the resin, nanoclays could potentially increase the strength of wood composites as well as reduce production costs.

This study focuses on the addition of organoclays to PF-resin with the aim of improving bond strength and by extension, MBP-OSL board properties. In particular, we investigate the creep behavior and internal bond (IB) strength of MPB-OSL as well as cured phenol/formaldehyde (PF) resin with different organoclay types and concentrations. In addition we evaluate the applicability of time-temperature superposition (TTS) to predict the long-term creep behavior of organoclay reinforced MPBOSL.

\section{MATERIALS and METHODS}

\subsection{Materials and Sample Preparation}

The MPB killed lodgepole pine strands (150 $\mathrm{mm}$ long, $25 \mathrm{~mm}$ wide and $1 \mathrm{~mm}$ thick) were provided by Ainsworth Lumber Co. Ltd., Grande Prairie, AB, Canada. The PF resin (Cascophen OSF-59FLM) was obtained from Hexion Canada, and the organoclays were purchased from
Southern Clay Products Inc. (Austin, TX, USA). The three organoclays used in this study were Cloisite $\mathrm{Na}^{+}$, a natural montmorillonite (MMT), and Cloisite 10A (10A), and 30B (30B), natural montmorillonite modified with quaternary ammonium salts. Fig. 1 shows the structure of the salts for the respective organoclays.

The strands and resin were blended in a 1.5 $\mathrm{m}$ diameter and $0.6 \mathrm{~m}$ depth drum blender. The blending process was as follows: the required organoclay was mixed with $\mathrm{PF}$ resin at 1,000 rpm for 6 minutes with a Hamilton Beach 730 C DrinkMaster Chrome Classic Drink Mixer; the strands for one panel were then placed in the blender, and the resin/organoclay mixture was sprayed on the strands using a nozzle under a pressure of about $200 \sim 350 \mathrm{kPa}(30 \sim 50 \mathrm{psi})$. The blending had a rotating rate of $100 \mathrm{rpm}$ and it lasted 6 minutes for each batch. Five organoclay formulations were used: $0 \%$ organoclay as a control, 2\% MMT, 5\% MMT, 2\% $10 \mathrm{~A}$, and $2 \% 30 \mathrm{~B}$ (all weight percentage of organoclay based on total amount of PF resin). The blended strands were hand formed into an OSL mat which was placed in the pre-heated press at $50^{\circ} \mathrm{C}$, and pressed for $2,400 \mathrm{~s}$ at a target platen temperature of $180^{\circ} \mathrm{C}$ to yield a uniform vertical density profile. After cooling to room temperature, each board was cut into two types of samples for the short-term creep test: one cut in parallel to strand alignment direction and the other perpendicular to strand alignment with a size of $35 \mathrm{~mm}$ long by $12 \mathrm{~mm}$ wide by $2.5 \mathrm{~mm}$ thick for dynamic mechanical analysis (DMA). Three replicate panels were made for each treatment with the same target density of $600 \mathrm{~kg} / \mathrm{m}^{3}$ at $1 \%$ moisture content.

For the short-term creep tests, cured PF resin samples were prepared at 2 and 5\% MMT, 10A and $30 \mathrm{~B}$ organoclay loadings respectively. Test specimens were prepared by mixing the appropriate amount of organoclay with PF resin in a 
$250 \mathrm{ml}$ beaker, which was vigorously stirred at room temperature for $30 \mathrm{~min}$ and heated to $50^{\circ} \mathrm{C}$ for $30 \mathrm{~min}$ to remove air bubbles. The mixture was then cast into oven-baked clay molds (the same size as the OSL specimens used for DMA) and heated at $120^{\circ} \mathrm{C}$ for 60 min. The specimens were then removed from the molds and fully cured in an oven at $150^{\circ} \mathrm{C}$ for another $60 \mathrm{~min}$. All samples were dried in a vacuum-desiccator over $\mathrm{P}_{2} \mathrm{O}_{5}$ for at least 4 weeks prior to DMA testing.

\subsection{Dynamic Mechanical Analysis (DMA)}

\subsubsection{Determination of the Linear Visco- elastic Region}

The linear viscoelastic region (LVR) analysis was performed on a TA Instruments Q800 DMA using a dry-nitrogen purge of the sample chamber with a dual-cantilever clamp. Samples were secured with a clamping torque of $\sim 110$ $\mathrm{N} \cdot \mathrm{cm}$. The LVR of the samples was determined using a strain sweep, where the sample was sinusoidally deformed with increasing amplitude per strain at a constant frequency (1 $\mathrm{Hz}$ ). The LVR tests were conducted at $50^{\circ} \mathrm{C}$. All dynamic scans were performed at a stress rate of $1.0 \mathrm{MPa} \cdot \mathrm{min}^{-1}$. Samples were rapidly cooled or heated to a desired temperature and equilibrated for $10 \mathrm{~min}$ prior to scanning. All samples were replicated a minimum of 10 times.

\subsubsection{Short-term Creep Tests}

All creep tests were performed using a dual-cantilever clamp on a TA Instruments Q800 DMA. Short-term creep tests were carried out for $10 \mathrm{~min}$ at $10^{\circ} \mathrm{C}$ intervals covering a temperature range from -10 to $120^{\circ} \mathrm{C}$. The applied stress was 6.0 MPa. Each sample was mounted into the dual cantilever clamp and equilibrated at the test temperature for $5 \mathrm{~min}$ (soak time) prior to starting the experiment. The resulting data was plotted as the log of creep compliance as a function of log time. The data at other temperatures were shifted along the log time axis to $40^{\circ} \mathrm{C}$ (the reference temperature) using the Time-Temperature-Superposition (TTS) data analysis software that came with the DMA (TA Data Analysis 2000 V5.6) to generate a master curve. Each short-term creep test was replicated 3 times.

\subsection{Internal Bonding Strength Tests}

To determine if the organoclays were compatible with the resin a series of Internal Bond (IB) strength tests were performed in accord with ASTM D1037, 2000 using a Sintech 40D Universal Testing Machine. All IB strength tests were replicated ten times.

\section{RESULTS and DISCUSSION}

\subsection{Creep Behavior of PF Resin Cured Samples with Organoclays}

\subsubsection{Determination of Linear Viscoelastic Region (LVR)}

Prior to creep analysis, the linear viscoelastic region (LVR) had to be determined for the $\mathrm{PF}$ resin samples in order to select the stress value sufficiently large enough to ensure good deformation for creep measurements. This is particularly important because the linear viscoealstic properties of polymers are both time and temperature dependent (William et al., 1955; Aklonis et al., 1983; Faucher, 1959; Nunez et al., 2004). The resulting strain-stress plot was constructed by applying a stress rate $(1.0 \mathrm{MPa}$. $\min ^{-1}$ ) on the samples at an isothermal temp- 
Table 1. Maximum stress level of cured PF resin samples with organoclays as determined from the LVR measurements at $50^{\circ} \mathrm{C}$

\begin{tabular}{ccc}
\hline Sample & $\begin{array}{c}\text { Ultimate Stress } \\
(\mathrm{MPa})\end{array}$ & $\begin{array}{c}\text { Standard } \\
\text { Deviation } \\
(\mathrm{MPa})\end{array}$ \\
\hline \hline resin-control & 11.7 & 1.7 \\
resin-MMT 2\% & 10.7 & 1.2 \\
resin-MMT 5\% & 10.4 & 1.4 \\
resin-MMT 10\% & 9.8 & 0.9 \\
resin-10A 2\% & 10.1 & 1.5 \\
resin-10A 5\% & 9.7 & 0.8 \\
resin-30B 2\% & 8.9 & 0.6 \\
resin-30B 5\% & 8.9 & 0.3 \\
\hline
\end{tabular}

erature. An example of the results from the LVR analysis is shown in Fig. 2; strain increases linearly with stress up to the ultimate strength where the sample fails in brittle fashion.

The ultimate strength of the resin/organoclay mixtures ranged between 8.9 to $11.7 \mathrm{MPa}$ with considerable scatter; the overall standard error was found to be $14.8 \%$ (Table 1). For example, adding 2 or $5 \%$ of $30 \mathrm{~B}$ organoclay decreased the ultimate strength from 11.7 to $8.9 \mathrm{MPa}$. This may be that the cured organoclay reinforced resin sample became less flexible and thus the maximum stress level decreases. As a consequence, a stress of $6.0 \mathrm{MPa}$ was selected for the creep analysis.

\subsubsection{Creep Behavior of Organoclay Rein- forced Cured PF Resin Samples}

Time-temperature superposition (TTS) is one of the most useful extrapolation techniques to characterize viscoelastic properties of a material at various temperatures over an experimentally convenient time (Leaderman et al., 1942; Turi, 1997; Vaidyanathan et al., 2003; Tajvid et al., 2005). The data taken at various temperatures

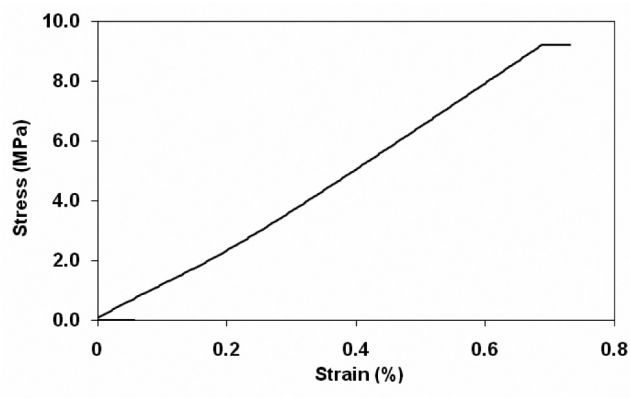

Fig. 2. Typical strain-stress plot of resin-MMT 5\% used for the determination of the linear viscoelastic region. The stress rate was $1.0 \mathrm{MPa}$ $\cdot \min ^{-1}$ at $50^{\circ} \mathrm{C}$.

can be superimposed to a reference temperature of interest to extend the time range of response; curve is referred to as the master curve and represents the time response of the material at the reference temperature (Turi, 1997).

The empirical relationship between time and temperature effect of stress on the deformation process can be formulated using two mathematical equations, William-Landel-Ferry (WLF) and Arrhenius equations (William et al., 1955; Alklonis et al., 1983). The WLF equation is expressed as Equation 1:

$$
\log a_{T}=\frac{-C_{1}\left(T-T_{0}\right)}{\left(C_{2}+T-T_{0}\right)}
$$

Where $\mathrm{a}_{\mathrm{T}}$ is the horizontal shift factor, $\mathrm{T}_{0}$ is the reference temperature $(\mathrm{K})$, and $\mathrm{T}$ is the temperature at which the creep test is performed $(\mathrm{K})$. The WLF equation describes the time-temperature stress response behavior of amorphous polymers at near the glass transition temperature (William et al., 1955).

The second equation is commonly used to relate the shift factor with respect to temperature. The Arrhenius equation is described as Equation 2:

$$
\ln a_{T}=\frac{-E_{a}}{R}\left(\frac{1}{T}-\frac{1}{T_{0}}\right)
$$



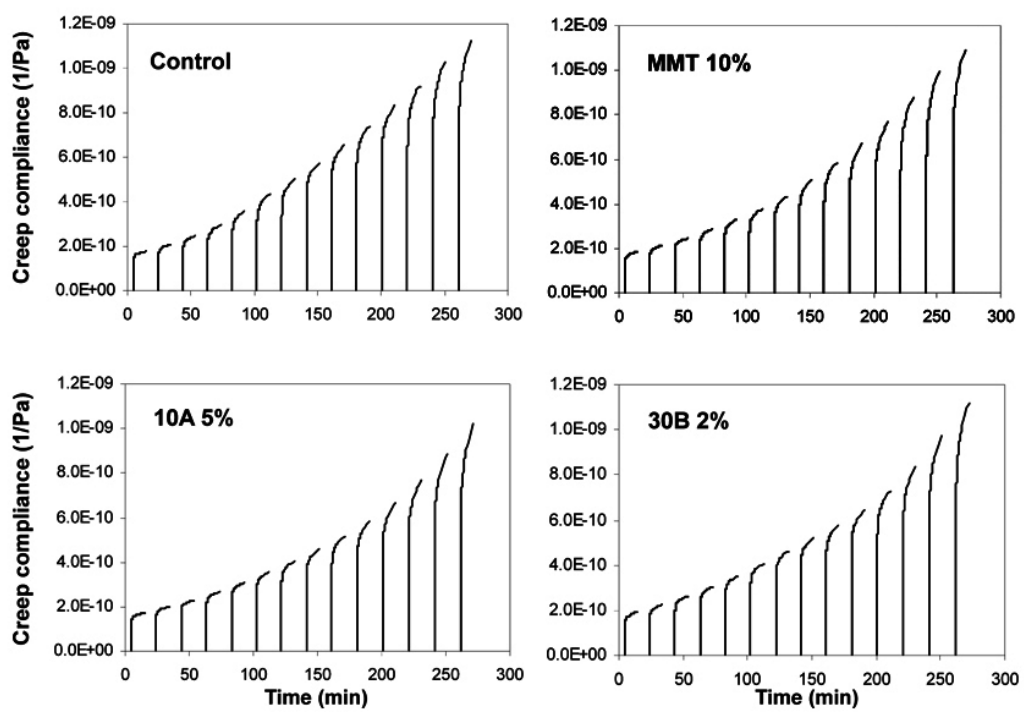

Fig. 3. Creep compliance curves of control, MMT 10\%, 10A 5\% and 30 B 5\% for 10 min loading at different temperatures between -20 and $110^{\circ} \mathrm{C}$ at $10^{\circ} \mathrm{C}$ intervals.

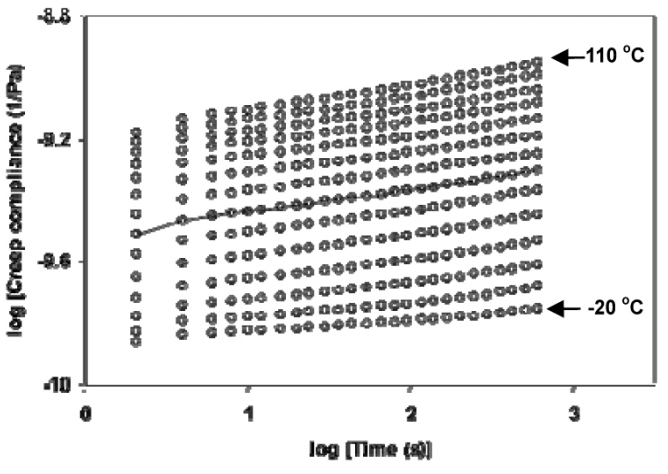

Fig. 4. Log creep compliance versus log time at different temperatures for PF-resin control sample. The solid line is the reference temperature of $40^{\circ} \mathrm{C}$.

Where $E_{a}$ is the activation energy associated with the relaxation transition and $\mathrm{R}$ is the universal gas constant. The Arrhenius equation is commonly used to describe the viscoelastic properties associated with the secondary glass transition event or for glass transition associated with semi-crystalline polymers (Aklonis et al.,
1983; Faucher et al., 1959; Nunez et al., 2004).

A prolonged time and temperature effect on the deformation of amorphous materials of semicrystalline MPB strands and resin could be evaluated by short-term creep compliance changes at different temperatures of isothermal constant stress followed by use of the WLF equation to relate prolonged period effects on compliance if a shift factor was satisfactorily employed (Faucher et al., 1959; Nunez et al., 2004). Those compliance changes are the well-established correspondence between time and temperature effects on creep deformation of materials with constants stress conditions near the glass transition range (William et al., 1955; Faucher et al., 1959; Nunez et al., 2004). Typical illustrative examples of creep compliance profiles for the 4 sample types (control, MMT, 10A, and $30 \mathrm{~B}$ ) as a function of time and temperature obtained from the short-term creep tests are shown in Fig. 3.

Fig. 4 shows a log-log plot of creep compliance versus time of a set of 14 different tem- 

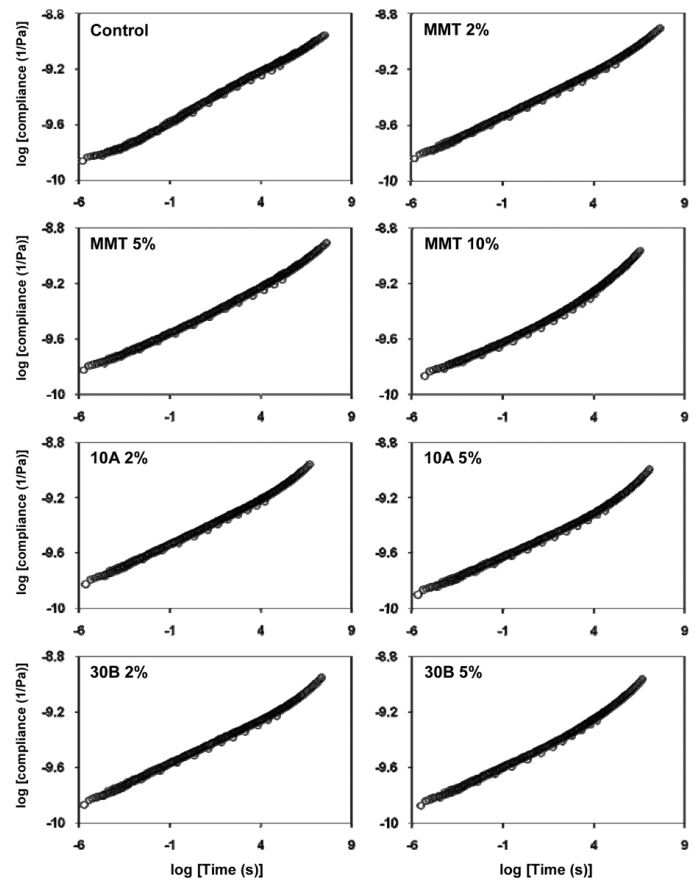

Fig. 5. Master curves of TTS creep made from actual creep data for PF resin samples.

peratures for $\mathrm{PF}$ resin-control sample with $40^{\circ} \mathrm{C}$ reference temperature (a solid line). All curves were then horizontally shifted along the log time axis to merge with the reference temperature $\left(40^{\circ} \mathrm{C}\right)$ using the TTS analysis software. The results of such shifting curves (master curves) are shown in Fig. 5 and all smooth master curves circles data points were obtained for all samples.

The shift factor data were fitted to the WLF equation by the least square fit using TTS software in order to evaluate the validity of TTS analysis (Fig. 6). The overall data standard error of the WLF equation fit was approximately 6.0 to $11.4 \%$ for all PF-resin samples. The good fits of the shift factor data to the WLF equation were observed and show no significant difference in all resin samples.

Even though a similar trend was observed in
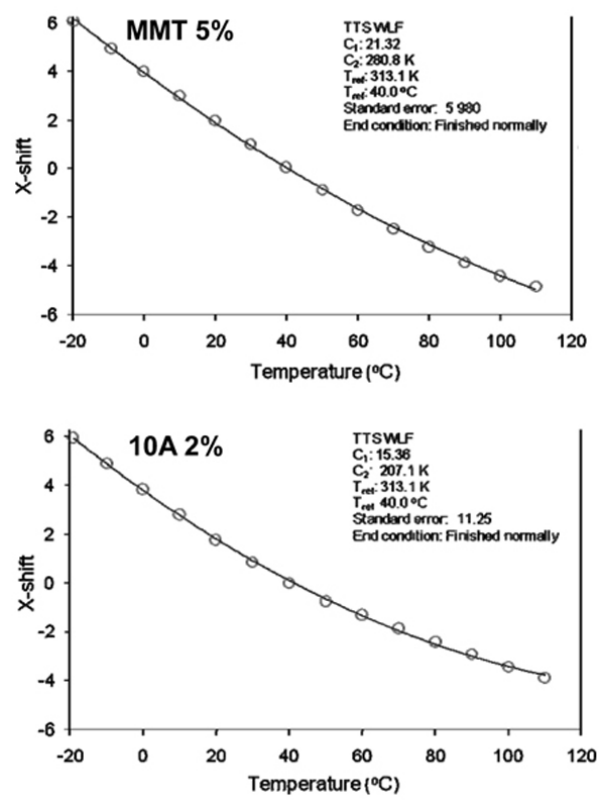

Fig. 6. Plots of shift factor versus temperature for PF-resin samples. Open circles are shift factor from TTS creep data and solid curves are the WLF model.

all samples, in higher clay content samples (MMT 10\%, 10A 5\% and 30B 5\%) the master curves trend (Fig. 5) showed slightly higher creep deformation at longer times. These differences in master curves between among composite resins may thus indicate dissipation of stored energy through deformation processes and thus affect fracture propagation (Vaidyanathan et al., 2003), indicating that the ability of bonding is slowly decreased at longer times.

\subsection{Creep behavior of MPB-OSL with Organoclays}

\subsubsection{Determination of Linear Viscoelastic Region (LVR)}

Again the LVR was determined for the MPB-OSL with organoclays samples to select 
Table 2. Maximum stress level of MPB-OSL with organoclays as determined from the LVR measurements at $50^{\circ} \mathrm{C}$

\begin{tabular}{crc}
\hline Sample & $\begin{array}{c}\text { Ultimate } \\
\text { Stress (MPa) }\end{array}$ & $\begin{array}{c}\text { Standard } \\
\text { Deviation } \\
(\mathrm{MPa})\end{array}$ \\
\hline \hline MPB-OSL-control-A & 9.6 & 0.9 \\
MPB-OSL-control-B & 10.0 & 0.8 \\
MPB-OSL-MMT 2\%-A & 9.7 & 1.7 \\
MPB-OSL-MMT 2\%-B & 10.1 & 0.3 \\
MPB-OSL-10A 2\%-A & 9.0 & 1.0 \\
MPB-OSL-10A 2\%-B & 9.4 & 1.0 \\
MPB-OSL-30B 2\%-A & 9.6 & 1.0 \\
MPB-OSL-30B 2\%-B & 9.2 & 1.1 \\
\hline
\end{tabular}

the stress level for the short-term creep tests. The strain-stress plot was constructed from applying a stress rate $\left(1.0 \mathrm{MPa} \cdot \mathrm{min}^{-1}\right)$ to samples at each isothermal temperature. The average maximum stress level (the stress before the sample was broken) ranged from 9.0 to 10.1 $\mathrm{MPa}$ (standard error 17.8\%) in all of the tested samples and showed no significant difference as shown in Table 2. As a consequence of this analysis, a stress of $6.0 \mathrm{MPa}$ was selected for creep testing all the samples.

\subsubsection{Creep behavior of MPB-OSL with Organoclays}

Typical results of creep compliance profiles of the four samples (control-A, and MMT $2 \%$-A, 10A 2\%-A and $30 \mathrm{~B} 2 \%-\mathrm{A}$ ) as a function of time and temperature were obtained from short-term creep tests. As described above all curves were then horizontally shifted along the log time axis to merge with the reference temperature $\left(40^{\circ} \mathrm{C}\right)$ by TTS analysis software. The results of such shifting curves (master curves) are shown in Fig. 7. The overall data standard error of the WLF equation fit was approximately 13.4 to $19.7 \%$ for all OSL samples. Relatively good fits of the shift factor data to
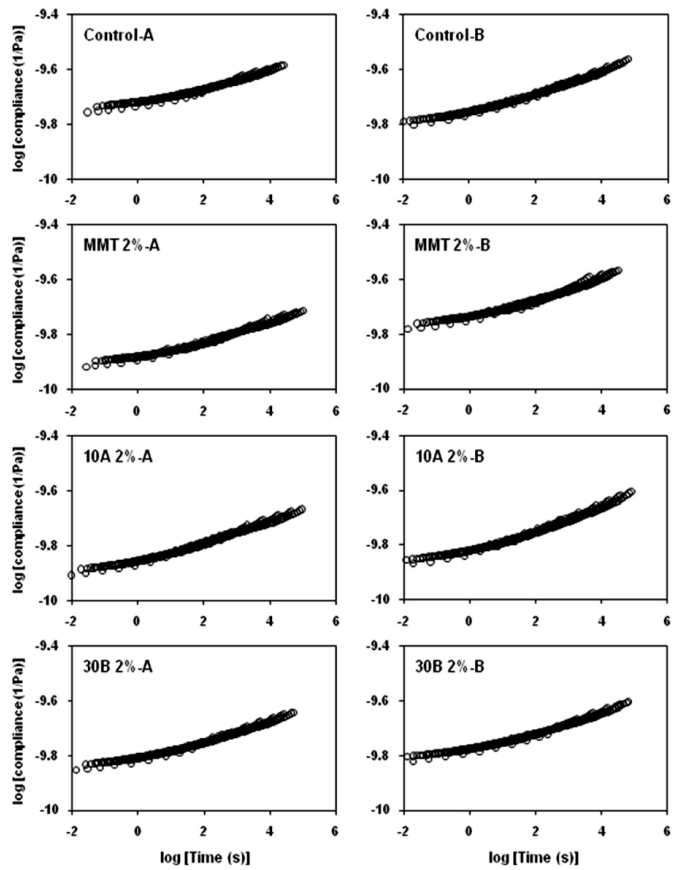

Fig. 7. Master curves of TTS creep data made from actual creep data for MPB-OSL samples.

the WLF equation were observed (data not shown).

OSL made from semicrystalline MPB strands and resin and with rigid organoclays may show a great variety of mechanical properties, depending on the composition and the processing conditions. The final properties of the MPBOSL are governed by the individual properties of the components as well as by the interactions developed at the matrix/organoclay interface. The effect of the addition of organoclays to MPB-OSL on the creep behavior is shown Fig. 7. As the organoclay was added, the deformation decreased. A similar trend was observed in all samples but the overall observed creep deformation was less in the order $10 \mathrm{~A} 2 \%>$ MMT 2\%>30B 2\%>control and these differences in master curves between among MPBOSL samples may thus indicate dissipation of 
Table 3. Internal bonding strength test results for organoclay MPB-OSL samples

\begin{tabular}{ccc}
\hline Sample & $\begin{array}{c}\text { IB strength } \\
(\mathrm{MPa})\end{array}$ & $\begin{array}{c}\text { Standard } \\
\text { deviation } \\
(\mathrm{MPa})\end{array}$ \\
\hline \hline MPB-OSL control & 0.28 & 0.08 \\
MPB-OSL MMT 2\% & 0.37 & 0.06 \\
MPB-OSL MMT 5\% & 0.32 & 0.09 \\
MPB-OSL 10A 2\% & 0.40 & 0.06 \\
MPB-OSL 30B 2\% & 0.33 & 0.08 \\
\hline
\end{tabular}

stored energy through deformation processes and thus affect less fracture propagation.

\subsection{Internal Bonding (IB) Strength for MPB-OSL with Organoclays}

IB strength tests were conducted to investigate the internal bonding property by addition of organoclays into OSL. The results (Table 3) indicate that organoclay $10 \mathrm{~A}$ stands out with the highest IB strength and likewise creep results of MPB-OSL; a similar trend was observed in all samples. These indicate that the bonding ability of resin was likely increased due to the addition of organoclays in the order $10 \mathrm{~A} 2 \%>$ MMT $2 \%>30 \mathrm{~B} 2 \% \geq$ MMT $5 \%$. These could be a result of better dispersion of the particles in the organoclays in the order $10 \mathrm{~A} 2 \%>$ MMT $2 \%$ $>30 \mathrm{~B} 2 \%$ during the mixing step of resin and organoclay because the organoclay $10 \mathrm{~A}$ has a phenyl group (Fig. 1), which has a similar structure to phenol and makes them easier to mix together resulting in improved final adhesion at the matrix/organoclay interphase. However, organoclay $30 \mathrm{~B}$ has hydroxyl groups (Fig. 1) and could not be easily mixed with resin and had poor dispersion of organoclay.

\section{CONCLUSIONS}

The creep TTS analysis of the resin cured samples and MPB-OSL with organoclays was performed in this study. The results indicate that there is no significant difference between resin composite samples but some difference between MPB-OSL samples. The observed creep deformation and IB strength properties were improved as adding organoclays to resin in the order (of) $10 \mathrm{~A} 2 \%>$ MMT $2 \%>30 \mathrm{~B}$ $2 \%>$ control, indicating the bonding ability of resin was likely increased due to adding organoclays. In addition, TTS analysis can be expected to work and possibly predict the long-term creep behavior of MPB-OSL samples. Nevertheless, the results of this study must be used with caution because creep behavior is a complex phenomenon that could be dependent on a variety of parameters, such as the stress level, temperature, and environmental conditions.

\section{REFERENCES}

1. Morford, S., D. Moshenko, E. Proteau, and A. Thomson. 2004. An assessment of the research and technical information need of forestry operators in British Columbia, (www.forrex.org/publications).

2. Natural Resources Canada. Mountain Pine Beetle Initiative: Epidemic Risk Reduction and Value Capture R\&D Strategy. Natural Resources Canada, Canadian Forest Service, Pacific Forestry Centre, Victoria, B.C., 2004.

3. Feng, M. W. and R. M. Knudson. 2007. Effect of $\log$ rehydration on quality of OSB strands manufactured from beetle-killed lodgepole pine. Forest Prod. J. 51: $35 \sim 42$.

4. Oudjehane, A. and F. Lam. 2008. Development of thick MPB strand based wood composites. Annual report MDP 08-066.

5. Oudjehane, A. and F. Lam. 2008. High temperature pre-heating of MPB logs for optimized processing into strand based composites. Annual report MDP 08-074.

6. Oudjehane, A. and F. Lam. 2009. Development of innovative preheating technology for MPB en- 
gineered wood product. Annual report MDP 09-063.

7. Pinnavaia, T. and G. Beall. editors. 2000. Polymerclay nanocomposites. London, UK, Wiley \& Sons.

8. Lei, W., Y. Deng, M. Zhou, L. Xuan, and Q. Feng. 2006. Mechanical properties of nano $\mathrm{SiO}_{2}$ filled gypsum particleboard. Trans. Nonferrous. Met. Soc. China. 16: $361 \sim 364$.

9. Lin, Q., G. Yang, J. Liu, and J. Rao. 2005. Study on the property of Nano-SiO2/urea formaldehyde resin. Scientia Silvae Sinicae 41: 129 135 .

10. Lei, Y., Q. Wu, C. M. Clemons, F. Yao, and Y. $\mathrm{Xu}$. 2007. Influence of Nanoclay on Properties of HDPE/Wood Composites. J. Appl. Polym. Sci. 106: $3958 \sim 3966$.

11. ASTM. 2000. Construction (wood). In Annual book of ASTM Standards, ASTM D1037, American Society for Testing and Materials.

12. William, M. L., R. F. Landel, and J. D. Ferry. 1955. The temperature dependence of relaxation mechanisms in amorphous polymers and other glass-forming liquids. J. Am. Chem. Soc. 77: $3701 \sim 3707$.

13. Aklonis, J. J. and W. J. MacKnight. 1983.
Introduction to polymer viscoelasticity; Wiley: New York.

14. Faucher, J. A. 1959. Viscoelastic behaviour of polyethylene and polypropylene. Trans. Soc. Rheol. 3: $81 \sim 93$.

15. Nunez, A. J., N. E. Marcovich, and M. I. Aranguren. 2004. Analysis of the creep behavior of polypropylene-woodflour composites. Polym. Eng. Sci. 44: $1594 \sim 1603$.

16. Leaderman, H. 1943. Elastic and creep properties of filamentous materials and other high polymers. Washington D.C., Textile Foundation.

17. Turi, E. A. 1997. Thermal characterization of polymeric materials, 2nd ed., Academic: San Diego.

18. Vaidyanathan, T. K., J. Vaidyanathan, and Z. Cherian. 2003. Extended creep behavior of dental composites using time-temperature superposition principle. Dental Mater. 19: 46 53.

19. Tajvid, M., R. H. Falk, and J. C. Hermanson. 2005. Time-temperature superposition principle applied to a kenaf-fiber/high-density polyethylene composite. J. Appl. Polym. Sci. 97: 1995 2004. 